\title{
APLL E LINHA D’ÁGUA: UTOPIA, DIÁLOGO E DISCIPLINA
}

\author{
Ligia Chiappini Moraes Leite*
}

Já tive oportunidade de narrar em outros momentos ${ }^{1}$ algo dessa história, e, se penso valer a pena repeti-la um pouco aqui é por ter conhecimento da permanência de muitos dos problemas do ensino brasileiro que minha geração vivenciou e por reconhecer a necessidade de passar a tocha às novas gerações, interessadas em trabalhar para superá-los. A Associação de Professores de Língua e Literatura (APLL) e a sua revista, Linha d'Água, foram criadas e se mantêm também com essa finalidade.

Obra de uma juventude cansada da ditadura e por ela precocemente amadurecida, a APLL e a Linha d'Água beneficiaram-se dessa combinação da utopia juvenil com a ação responsável e perseverante. Por isso talvez se possa dizer que nasceram para ficar, mesmo levando em conta as fases difíceis por que passaram e as outras pelas quais ainda poderão passar, já que estas são inevitáveis quando se trata de iniciativas que, como é o caso aqui, dependem basicamente de trabalho voluntário.

A primeira fase do meu envolvimento, enquanto universitária, com os problemas de ensino na minha área de estudo -- teoria literária e literatura comparada -- vai aproximadamente de julho de 1977 a julho de 1980. É o que já chamei um tanto a sério, um tanto de modo auto-irônico, a fase "heróica" da descoberta de um campo de pesquisa e de intensa militância junto às associações docentes, em tempo de greves com grande participação de professores universitários e do que, na época, chamávamos de primeiro e segundo graus

Ainda na primeira metade da década de 70, instigada pelas indagações e inquietações advindas da prática docente nos cursos de Introdução aos Estudos Literários, para estudantes do primeiro ano do curso de Letras da USP e, simultaneamente, da docência em cursos de atualização e reciclagem, oferecidos aos professores da rede pública do Estado de São Paulo, iniciei um trabalho mais sistemático de pesquisa, aliada à militância junto à Adusp e à Apeoesp, tentando entender melhor os problemas diagnosticados e suas causas, para propor algumas soluções. Aos poucos essa pesquisa e essa militância foi incluindo outras pessoas, da própria Universidade e da escola, sobretudo pública, embora houvesse também alguns de escolas particulares. Algumas destas, aliás, tiveram um papel importante na época da ditadura, como bolsões de resistência e laboratório de novas propostas educacionais.

\footnotetext{
${ }^{*}$ Freie Universitat Berlin, Lateinamerika-Institut.

${ }^{1}$ Veja-se, entre outros, os textos: Chiappini Moraes Leite e de Marco, Valéria. "Apresentação da APLL", in_Almanaque, n. 11. S. Paulo, Ed. Brasiliense, 1980 e Chiappini Moraes Leite. "Apresentação de Linha d'Água”. In: Linha d'Água, número especial com as comunicações ao Encontro da Sociedade Brasileira para o progresso da Ciência, S.B.P.C., de 1994. Ambos os textos foram republicados, já no século XXI, em Chiappini, Ligia. Reinvenção da Catedral: língua, literatura, comunicação, novas tecnologias, políticas de ensino. S. Paulo, Cortez Editora, 2005. P.327-335.
} 
Nos cursos de reciclagem ou treinamento que as universidades privadas e públicas ofereciam a professores da rede, pude descobrir que havia (e talvez ainda haja) um profundo abismo entre as instituições universitárias e as responsáveis pelo ensino básico e médio. Antes de tudo, as condições de trabalho nessas escolas (principalmente naquelas que pertenciam à rede pública, mas mesmo em muitas escolas particulares) eram, então, mais que hoje, muito precárias. Os Salários muito baixos obrigavam (e obrigam ainda) os professores a dar muitas aulas a fim de obterem um mínimo para o seu sustento. Uma das conseqüências era e continua sendo ter o corpo docente desses níveis pouco tempo para preparar suas aulas, para corrigir os trabalhos dos alunos e, por certo, quase nenhum tempo para estudar.

Essa constatação despertou-me para a necessidade de uma dupla militância: de um lado, junto à escola pública e às secretarias de educação e MEC, juntamente com entidades de classe, como a APEOESP. De outro lado; junto à Universidade. No primeiro caso, tratava-se de defender e conquistar melhores condições de trabalho para os colegas do ensino fundamental e médio, o que significava apoiar a luta da categoria por melhores salários, por escolas decentes, por tempo remunerado de planejamento e formação permanente. Já no segundo caso; tratava-se de reivindicar, tanto por meio da ADUSP quanto diretamente nos grêmios universitários e junto à Reitoria, que os docentes, dispostos a trabalhar nos programas de formação permanente do professor e de reformulação curricular da escola pública, tivessem o reconhecimento desse trabalho pela Academia, ainda excessivamente fechada na avaliação da pesquisa tradicional, deixando o ensino e a extensão, respectivamente, em segundo e terceiro plano.

A APLL nasceu em 1977, quando um grupo de professores da Universidade de São Paulo e da Unicamp, em que me incluía, organizou um simpósio na Sociedade Brasileira de Progresso à Ciência, que constituia o único grande fórum da intelectualidade durante a ditadura militar. $O$ tema que levamos para o debate era "Teoria da Literatura e Educação". Havia no público muitos professores do então chamado ensino de primeiro e segundo graus, além dos professores e estudantes universitários. Depois de uma discussão bastante animada sobre o tecnicismo dos estudos literários na Universidade (era o auge do chamado estruturalismo nos estudos literários e lingüísticos) e a insuficiência do trabalho com os textos na escola elementar e média, nasceu a idéia de criar uma associação que integrasse professores dos três graus de ensino para, juntos, ultrapassarmos o diagnóstico ainda impressionista e, em alguns casos, preconceituoso, buscando aprofundar o estudo da realidade para tentar transformá-la positivamente. Começávamos a perceber já aí que simplesmente apontar defeitos e reivindicar melhores condições de trabalho, embora necessário, era insuficiente para resolver os problemas levantados. Era preciso, ao lado da militância por melhores condições de trabalho, criar um espaço de pesquisa, para melhor conhecer e combater a escola da ditadura, em que a língua e o estudo da língua eram visivelmente um dos principais instrumentos de discriminação. ${ }^{2}$

É importante sublinhar o fato de termos criado a APLL no âmbito da SBPC, à qual ela se filiaria, ao lado de outras tantas sociedades científicas, pois isso nos ajudaria

\footnotetext{
${ }^{22}$ Esse problema continua atual, embora haja diferenças. É o que parecem comprovar alguns trabalhos mais recentes, como as notas de Vanderléia Oliveira e Claudio Mello, datadas de 25.5.2009 que comentam o livro Invasão da Catedral, ressaltando a sua atualidade. (acessado em 22.05.2010).
} 
a garantir não apenas a militância político-pedagógica, mas a perseverança no caminho da pesquisa séria, com a certeza de que esta não deve ser privilégio da Universidade.

Nesses tempos heróicos da APLL, dedicamos muitas horas de vida e trabalho, muitos sábados e domingos, muitos feriados e muito tempo de férias escolares para redigir,datilografar, envelopar, endereçar e enviar --por correio, é claro-- a correspondência aos sócios e sócias, cujos nomes e endereços constavam de um fichário que estávamos sempre atualizando, muitas vezes, por meio da consulta minuciosa à lista telefônica, como última tentativa de localizar quem desaparecia, por mudança de vida (escola, bairro ou até mesmo, profissão). E também fazendo boletins, preparando os encontros e deles participando ou planejando, compondo e revisando textos para a revista. Tudo isso sempre com muito entusiasmo e alegria. A alegria que dá o trabalho comunitário em prol de causas maiores, que transcendem os limitados interesses particulares.

Desde o início eu intuía que esse trabalho era necessariamente participativo. Por isso, já no começo dos anos 80 , falava das novas relações entre teoria e prática que somos obrigados a estabelecer quando em pesquisa se cruzam campos específicos como o dos estudos literários e lingüísticos de um lado, o educacional de outro. Em texto dessa época, escrevi que a pesquisa acadêmica, nesse caso, se redefine num processo mais amplo de pesquisa coletiva do qual os produtos individuais (teses, artigos, livros, conferências, aulas) seriam apenas resultados parciais. Atravessando um campo comum-- do trabalho quotidiano de alunos e professores - a pesquisa passava a ser entendida como um processo de cruzamento de respostas individuais, parciais, em constante reformulação. Por isso, o termo que utilizei em várias oportunidades para nomear a especificidade dessa pesquisa que tenta integrar dialeticamente o individual e o coletivo, a teoria e a prática didática, é "pesquisa-ação" ou pesquisa-participante-indicando tanto um trabalho de investigação como de militância, desenvolvido dentro e fora da Universidade, na sala de aula, nas revistas, nos congressos e nas assembléias tanto quanto no gabinete e nas bibliotecas.

$\mathrm{Na}$ verdade, tal pesquisa se impôs pela prática docente, como foi dito acima e se impôs de tal modo, com tal urgência e paixão, que retardou meus planos de seguir adiante com outra, já iniciada numa tese de doutoramento e que deveria ser aprofundada numa tese de livre-docência sobre o grande autor gaúcho, ainda pouco divulgado no centro do País, João Simões Lopes Neto.

Em 1978 desviei-me desse projeto, para fazer um pós-doutorado na França, sobre literatura e ensino. Lá fiz muitas leituras e realizei vários estágios em diferentes escolas e graus, assim como várias entrevistas com professores dos três níveis de ensino; participei de seminários, simpósios e debates em várias Universidades e fora delas, como os organizados pelo Movimento da Escola Moderna ${ }^{3}$ Um dos objetivos do projeto era verificar até que ponto os problemas encontrados no ensino da lingua e da literatura maternas num país de primeiro mundo tinha semelhanças com os nossos e até que ponto podíamos detectar, do lado brasileiro, situações específicas do sub-

\footnotetext{
${ }^{3}$ Movimento pedagógico, inspirado no pensamento e na prática do educador Celestin Freinet, também chamado de Movimento Freinet ou pedagogia Freinet e com base, entre outros nos princípios do diálogo, do texto livre (livre escolha do tema de redação pelos alunos), da gestão cooperativa da classe e na correspondência entre escolas, por meio de cartas coletivas (entre as classes) ou individuais (entre os alunos de classes e escolas diferentes, bem como entre seus professores), para troca de informações e experiências.
} 
desenvolvimento. Das indagações desse tempo resultou o livro intitulado Invasão da Catedral, publicado em 1983, publicado pela editora Mercado Aberto.

O projeto Lopes Neto não foi abandonado, mas foi postergado até 1986, para priorizar a intensa atividade de leitura, escrita e ação em torno do ensino da língua e da literatura, só vindo a completar-se em 1988, com a publicação do livro No entretanto dos tempos: literatura e história em João Simões Lopes Neto.

Voltando da França, em julho de 1979, recomecei a trabalhar na APLL, que, durante a minha ausência, no ano de 1978, já havia realizado o seu primeiro encontro anual e publicado seu primeiro boletim, para o qual também coolaborei, embora à distância. Pois mantinha correspondência assídua com as colegas e os colegas que a dirigiam, sobretudo com Teresa Pires Vara que, em 80, seria uma das principais idealizadoras da revista Linha d'Água e sua primeira diretora.

Em 1979, pude participar do segundo encontro, realizado nas chamadas "Colméias" da USP. Aí se formaram alguns grupos de trabalho, dentre os quais, um sob minha coordenação, que iria durar uns quatro anos, o grupo de formação permanente do professor, reunindo colegas dos três graus de ensino para pesquisar, a partir da observação da prática docente de cada um e do recurso a uma bibliografia selecionada, as soluções para a melhoria da formação continuada dos professores e do ensino de português ${ }^{4}$.

Esse grupo, que começou com vinte pessoas e terminou com sete, tinha um projeto piloto de integração da universidade e as escolas secundárias, que se baseava fundamentalmente na troca mútua de informação. Essa idéia era diferente dos cursos tradicionais de treinamento que as Universidades costumavam dar aos professores do ensino fundamental e médio. Nossas razões para sermos contra esses cursos tradicionais eram basicamente duas: 1) tais cursos consideravam esses professores como objetos, objetos vazios a serem preenchidos pelos especialistas das universidades; quase como robôs que recebem algumas idéias e passam-nas adiante, sem pensar; como "intelectuais subalternos", - segundo a famosa categoria de Gramsci; 2) esses cursos forçavam os professores a trabalhar durante suas férias e nos fins de semana ${ }^{5}$.

A nossa proposta de uma experiência piloto, que passamos logo a realizar, baseava-se num intercâmbio muito dinâmico entre os professores dos três graus de ensino, muito gratificante para todos. Observando as aulas uns dos outros, descobrimos nossas necessidades, desejos, forças e fraquezas. Aí tentávamos analisar as aulas uns dos outros e identificar o que poderíamos ler e discutir para melhorar a nossa prática, corrigindo o pragmatismo excessivo dos professores dos níveis elementar e médio, bem como a excessiva teorização (academicismo) dos universitários. Esse projeto supunha que os professores fossem pagos e trabalhassem nisso durante seu horário normal de aula.

Em 1980, na S.B.P.C., a APLL participou em diversas mesas redondas e simpósios, contribuindo para o tema geral do evento, que era "Ciência e Educação para

\footnotetext{
${ }^{4}$ Foram os seguintes os participantes mais assíduos desse grupo: Valéria de Marco (USP), Beatriz Marão Citelli (professora do então chamado primeiro grau, escola particular), Rosa Chimoni, Rita de Cassia e Vera Bloch (professoras dos chamados primeiro e segundo graus do Estado de São Paulo), Regina Maria Hubner (então professora dos mesmos graus, na Prefeitura de São Paulo, infelizmente já falecida) e eu.

${ }^{5}$ Mais recentemente esses cursos têm sido reformulados para melhor, mas a segunda restrição permanece.
} 
uma sociedade democrática". Aí se apresentaram alguns grupos de pesquisa-participante que, como o nosso, buscavam caminhos alternativos, principalmente para a escola pública. A novidade, em termos de S.B.P.C. é que, neles, havia, como expositores, não apenas professores universitários mas também dos outros níveis de ensino. Dessa presença e desse diálogo, nasceu um livro, publicado pela editora Cortêz: Lingua $e$ Literatura: o professor pede a palavra ${ }^{6}$. Alguns traços do trabalho do grupo de formação permanente e de outros grupos da A.P.L.L. podem ser encontrados nesse livro, no qual publicamos a maioria de nossas comunicações da SBPC desse ano. Tratase de um livro histórico porque registrou, pela primeira vez, em mais de trinta anos, que os professores da escola elementar e média iam à Reunião da SBPC para falar e não apenas para ouvir os especialistas.

Finalmente, cabe esclarecer que o grupo de formação permanente levou a essa S.B.P.C. o modelo que havíamos testado entre nós de formação pela interformação , teoricamente fundamentado, política e pedagógicamente justificado, discutindo uma proposta de implementação dirigida desse modelo nas escolas, proposta que foi aprovada pelos participantes e pelo público, e enviada às secretarias de educação do Estado e do Município. Estas, entretanto, nem tomaram conhecimento dela.

Linha d’Água foi criada nesse mesmo ano. Uma vez decididos os princípios básicos que a orientariam, formou-se uma comissão editorial, presidida pela Profa. Dra. Teresa Pires Vara, que nela se empenhou, batizando-a com esse belo nome e coordenando os seus primeiros números, ainda num formato oscilante, que se firmaria mais tarde, com um projeto editorial fixo, como nos conta Norma Goldstein no texto intitulado "Revista Linha d'Água: ensino de língua e literatura em debate" . A história da revista está intimamente imbricada com a história da APLL, cimo não poderia deixar de ser. Ambas fazem parte do mesmo projeto de criar espaços de diálogo entre a escola e a universidade para a produção de conhecimento e a ação transformadora.

Foi com esse objetivo central que, paralelamente à minha atuação na diretoria da associação, na sua revista e no grupo de Formação Permanente, com seu programa de estudos e estágios, bem como suas publicações, abri uma linha de pesquisa na pósgraduação sobre literatura e ensino. Alguns cursos, algumas dissertações de mestrado e algumas teses de doutorado começaram a nascer aí. As dissertações e teses se prolongariam até o final dos anos 90 . Essa linha de pesquisa continua até hoje dando frutos, na coleção que coordeno juntamente com Adilson Citelli, Aprender e ensinar com textos, editada e reeditada pela Cortez Editora. ${ }^{8}$

\footnotetext{
${ }^{6}$ Organização Valéria de Marco, Suzy Sperber e Ligia Chiappini, Ed. Cortez/S.B.P.C., São Paulo, 1981.

${ }^{7}$ Publicado em: http://www.fflch.usp.br/dlcv/apll/revista.html (acessado em 12.03.10).

${ }^{8}$ São as seguintes as dissertações e teses defendidas nessa linha de pesquisa, sob minha orientação: Teatro e escola no segundo grau (Roberto Sanchez, mestrado); A direção do esquecimento, literatura e ensino no segundo grau( Regina Maria Hubner, mestrado); Redação: limites e possibilidades (Beatriz Marão Citelli, mestrado); O paradidático, esse desconhecido (Maria Cecília M. Ramos, doutorado); Crônica de uma utopia, leitura e literatura infantil em trânsito (Maria Helena de Souza Martins, doutorado); Literatura Juvenil: Stella Carr, um enigma em suspenso (Maria Lucia Zoega , mestrado); Aventuras e desventuras de heróis menores (Maria Lucia Zoega, doutorado); "Literatura Infantil" (Ana Bonato Garcez Yazuda); "Osman Lins: mídia e educação em A Rainha dos Cárceres da Grécia" (Kasumo Kojima). Outros bolsistas do EFES, seja de iniciação científica (graduação), seja de mestrado ou doutorado, acabaram fazendo suas teses com os outros doutores, co-coordenadores do projeto ou com colegas da Faculdade de Educação da USP. É o caso de Conceição..., José Luiz Miranda, Eliane Nagamini, Marlete Tardeli, Stella ... , Magali ... . Alguns deles, como Marcela Evaristo e Ana Bonato G. Yasuda, continuam sua formação, respectivamente no mestrado e no doutorado, seja na Unicamp, seja na USP.
} 
Afora essas publicações que continuei co-coordenando, incentivando e revisando, desde 1997, quando vim para a Alemanha, não pude mais envolver-me diretamente nos cursos e pesquisas relacionados com a escola pública nem com o trabalho da APLL, pois isso só tinha sentido pelo acompanhamento atualizado da situação concreta local. Mas a APLL já havia alcançado um patamar de maturidade com nova equipe, nova sede e novos rumos, que pude acompanhar um pouco mesmo de longe, tanto por leituras quanto pelo contato que continuei tendo com novos e antigos participantes. Principalmente, com a equipe do antigo Estágio de Formação em Serviço EFES, e do que batizamos PÓS-EFES ${ }^{9}$. Com esse grupo ainda me reúno quase sempre que volto ao Brasil. E nessas voltas, há momentos de muita alegria, como foi a descoberta do trabalho, realizado no Cenpec, por. Regina Hubner ${ }^{10}$ e muita tristeza também, como a de receber, subitamente, em uma de minhas últimas estadias em São Paulo, para o lançamento de Reinvenção da Catedral, a notícia da morte dessa grande educadora, a quem o livro é dedicado.

Alegrias e as tristezas nos chegam também pela internet. Muito triste foi a confirmação recente, por esse meio, da perda de outra colega empenhada na luta por um ensino de qualidade e democrático: Conceição Aparecida de Jesus, que deixou muita saudade nas escolas e grupos de trabalho pelos quais passou, como é o caso do EFES e do PÓS-EFES. Mas, por outro lado, é muito gratificante o contato mantido por e-mail com pessoas que têm a vitalidade de Norma Goldstein, a quem se deve, em grande parte, a continuidade da APLL depois de sua saída da Casa de Cultura Japonesa. A Associação e seus membros entraram na era da internet com uma página bem desenhada e alimentada e, com isso, abriram mais espaço para possibilitar o diálogo entre profissionais dos três graus de ensino.

Sabemos com Celestin Freinet, defensor, como Paulo Freire, de uma pedagogia do diálogo, que, para dialogar efetiva e amplamente, é necessário utilizar sempre os meios técnicos mais avançados à nossa disposição no tempo e no espaço. Ele, que se

\footnotetext{
${ }^{9}$ Nome que demos por brincadeira ao grupo mais informal que continuou se reunindo sempre que havia oportunidade de unir a festa do reencontro ao planejamento de novas iniciativas, como foi o caso da coleção "Aprender e Ensinar com Textos", cujo projeto foi gerado num churrasco na casa de Marlete Carboni Tardelli, do qual participaram quase todos os autores dos 15 livros já publicados sob esse título geral, dado em um de nossos seminários públicos, realizados, ainda nos anos 90 , no Centro Maria Antonia, por João Wanderley Gerardi. .

${ }^{10}$ Entre outros projetos que se beneficiaram do idealismo e do profissionalismo de Regina Hubner, destaque-se o EducaRede Brasil, do qual tive oportunidade de falar mais longamente no livro acima citado, Reinvenção da Catedral. Esse projeto foi concebido em 2001, por Regina, juntamente com Andrea Bueno Buoro,Márcia Padilha Lotito,Fernando Moraes Fonseca Junior,Daniela Bertocchi e Giselle Beiguelman. Nas últimas vezes em que nos encontramos, ela falou com muito entusiasmo, desse trabalho e dessa equipe de colegas e amigos.
} 
serviu da tipografia, no início do século XX, certamente hoje seria um incansável internauta. Pois é esse meio que me permite, embora na última hora, enviar este texto aos organizadores do número comemorativo dos 30 anos da revista Linha d'Água. E, como o Site da APLL e da revista traz suficientes dados sobre as circunstâncias, os princípios e os objetivos com que foram criadas, não precisei repeti-los aqui, limitandome a dar este depoimento bastante pessoal, sobre como tudo começou ou melhor, sobre o quê minha memória guardou e que hoje me parece ter sentido partilhar. Na verdade, a própria existência do site desperta, por analogia e contraste, uma lembrança por ele hoje ressignificada. Trata-se de um detalhe anedótico com o qual termino estas já longas e um tanto descosidas reminiscências:

Em 1979, recém chegada da França, já como vice-presidente na gestão de Susy Sperber e já utilizando a sala, colocada gentilmente a nossa disposição na Casa de Cultura Japonesa ${ }^{11}$, uma das tarefas que me ocuparam os sábados foi a elaboração do boletim, para o qual usávamos máquina de escrever e mimiógrafo a álcool. Eu, pessoalmente, tinha um que utilizava seja para "rodar" os textos que deveriam ser distribuídos nos encontros e cursos, que organizávamos, seja para imprimir circulares e avisos, a enviar aos sócios reais e potenciais.

Como já me havia familiarizado com as propostas da pedagogia Freinet e ficado ainda mais convencida da importância da comunicação com e entre os professores de vários graus de ensino que aí se dispunham a dialogar, fui logo em busca do que havia de mais moderno, na época, para facilitar nossa tarefa: um mimiógrafo à tinta, objeto certamente desconhecido dos jovens na era da internet e do SMS. Tendo em vista os parcos recursos da Associação, que vivia das modestas anuidades, resolvi fazer uma pesquisa no mercado de mimiógrafos usados, da rua Santa Efigênia. Lá encontrei um bem velho, mas funcionando e a preço acessível, que levei para a USP, num fusquinha, também usado, conduzido por meu marido, Gerson de Moraes Leite, companheiro nessa e em outras aventuras apelelescas.

O precioso mimiógrafo foi bastante usado. Muito sujei as mãos nele. A cada vez, depois de terminar o trabalho do dia e de tirar a duras penas a tinta dos dedos e da maquininha, guardava-a, cuidadosamente, no armário ao fundo da sala, para deixar livre a única mesa de que dispúnhamos. Algumas pessoas não gostavam da minha invenção, justamente porque era muito difícil usar o tal mimiógrafo sem lambuzar tudo de tinta preta. Mas por muito tempo, foi o que nos valeu para imprimir nosso material, principalmente os boletins destinados aos sócios. Já a revista foi composta em off-set, um passo adiante na nossa tecnologia e nos recursos que nos permitiam terceirizar o serviço de impressão. Estávamos caminhando, ainda sem saber, para a APLL virtual que, certamente, ajudará a fortalecer, senão a reinventar, a APLL real.

\footnotetext{
${ }^{11}$ Nunca é tarde para agradecer publicamente a generosidade dos colegas da área de língua e literatura japonesa, do Departamento de Letras Orientais, que nos cederam o espaço discreta e gratuitamente por longos anos.
} 